Asian J. Med. Biol. Res. 2020, 6 (3), 519-524; doi: 10.3329/ajmbr.v6i3.49803

\author{
Asian Journal of \\ Medical and Biological Research \\ ISSN 2411-4472 (Print) 2412-5571 (Online) \\ www.ebupress.com/journal/ajmbr
}

\title{
Article \\ Knowledge of antibiotics and antibiotic usage behavior among the people of Dhaka, Bangladesh
}

Iftekhar Ahmed*, Md. Bodiuzzaman Rabbi, Marufa Rahman, Rehnuma Tanjin, Sharmin Jahan, Md Abu Adnan Khan and Sakina Sultana

Department of Pharmacy, Jahangirnagar University, Savar, Dhaka-1342, Bangladesh

*Corresponding author: Iftekhar Ahmed, Department of Pharmacy, Jahangirnagar University, Savar, Dhaka1342, Bangladesh. Phone: +8801755708242; E-mail: iftekhar2727@gmail.com

Received: 29 August 2020/Accepted: 26 September 2020/ Published: 30 September 2020

\begin{abstract}
Bangladesh is a developing country with a very high prevalence of antibiotic resistance where irrational use of antibiotics is very common. This cross-sectional survey was conducted to assess the knowledge of antibiotics and antibiotic usage behavior (Antibiotic use, self-medication, adherence to therapy) among the people of Bangladesh. The association between participants' knowledge of antibiotics and their antibiotic usage behavior was also analyzed. A cross-sectional survey based on a structured questionnaire was conducted in the Dhaka district. The questionnaire included questions about demographic information, participants' knowledge of antibiotics, and their recent antibiotic usage. The data analysis involved the use of descriptive statistics and multivariable logistic regression. Very few participants knew that antibiotics are not effective against most common colds (16.8\%), viruses (22.5\%), and pains (41.7\%). Most respondents (>75\%) knew that excessive use of antibiotics and failing to complete a course may render antibiotics less effective in the future. However, only $56.1 \%$ were aware of antibiotic resistance. About half (46.6\%) of the participants took antibiotics in the last six months, $20.5 \%$ of whom resorted to self-medication and $23.1 \%$ reported non-adherence to therapy. Greater knowledge of antibiotics was significantly associated with lower rates of self-medication $(p=0.037)$. Misconceptions about antibiotics and antibiotic misuse are very common in Bangladesh. The findings suggest that misconceptions about antibiotics and antibiotic misuse are very common in Bangladesh. To mitigate these problems, interventions comprised of educational campaigns and redesigning of the healthcare system and policies should be undertaken.
\end{abstract}

Keywords: antibiotic use; antibiotic resistance; knowledge; cross-sectional study; Bangladesh

\section{Introduction}

Excessive and irrational use of antibiotics is one of the causes of antibiotic resistance evolution while lowering of antibiotic consumption serves to impede the spread of resistance (Read and Woods, 2014). Several patientrelated factors are implicated in the spread of antibiotic resistance such as misconceptions regarding antibiotic use, self-medication of antibiotics, deviating from the appropriate dosage regimen, and influencing physicians' decisions in prescribing antibiotics (WHO, 2001). Therefore, unless public awareness is raised regarding the fundamental aspects of antibiotic action and usage, it is most unlikely that other measures in promoting the rational use of antibiotics will be very fruitful.

Bangladesh is a developing country with a high prevalence of antibiotic resistance where many of the first-line antibiotics have been reported to be mostly ineffective (Ahmed et al., 2019). Although the government prohibits the use of antibiotics without prescriptions, non-prescription use of antibiotics is widespread due to a lack of implementation of such laws (Hoque et al., 2020; Islam, 2006). Furthermore, most retail pharmacists in Bangladesh receive little or no training, and dispensing of drugs without prescriptions is very common (Ahmed et al., 2017). In a study conducted in Rajshahi, It was also found that $23.6 \%$ of the dispensed antibiotics were by the request of the customers (Saha and Hossain, 2017). This indicates that the public plays a major role when it 
comes to irrational antibiotic use in Bangladesh. While it is crucial to take regulatory measures to prevent nonprescription use as well as to train healthcare professionals, we believe identifying the gaps in public knowledge about antibiotics and implementing appropriate interventions to educate the people should be the very first step in promoting rational use of antibiotics and subsequent reduction of antibiotic resistance. Hence, this survey seeks to investigate 1) the knowledge of antibiotics among the people of Bangladesh, 2) the rates of antibiotic use, self-medication, and adherence to prescribed regimens, and 3) how participants' knowledge of antibiotics affects their antibiotic usage behavior. Although several studies have addressed antibiotic use and selfmedication in Bangladesh (Chowdhury et al., 2015; Fahad et al., 2010; Sutradhar et al., 2014), this is the first study to investigate the gaps in public knowledge and assess its impact on antibiotic usage behavior.

\section{Materials and Methods}

\subsection{Study design and sampling}

A cross-sectional survey was conducted from June to August of 2019 in Dhaka District - the capital of Bangladesh and the largest district in terms of population. Two of the six sub-districts of Dhaka (Dhaka City Corporation and Savar) were included in the survey. From each of the two regions, a random sample of the population was surveyed. Inclusion criteria for the selection of participants were: 1) adults age 18 years and above; 2) familiar with antibiotics; 3 ) provided written consent to participate in the survey. The sample size was determined using Raosoft ${ }^{\circledR}$ sample size calculator (Raosoft). Based on a 5\% margin of error and a confidence level of $95 \%$, the minimum required sample size was 385 . However, we surveyed 450 people, and 429 were included in the final statistical analysis after some of the responses were excluded from analysis because of missing data.

\subsection{The questionnaire}

The questionnaire was comprised of three segments. The first part collected the basic demographic information (Gender, Age, and Education) of the participants. The second part contained ten questions and statements pertaining to antibiotic action, usage, and resistance intended to evaluate the knowledge of the participants. The participants had to select either of the three answer choices (Yes/No/Not Sure for questions; Agree/Disagree/Not sure for statements). Part three contained questions about the participants' use of antibiotics (Antibiotic use, self-medication, and completion of therapy) within the last six months. In this study, self-medication has been defined as the taking of antibiotics without a doctor's prescription, rather by self-initiative, or by the advice of family/friends, or retail pharmacists.

\subsection{Statistical analysis}

Data analysis was done in IBM SPSS, version 25. The demographic characteristics of the participants and their responses to individual questions were reported using descriptive statistics. To identify the association between participants' knowledge of antibiotics and their practices related to antibiotic usage (recent use, self-medication, and completion of therapy), multivariable logistic regression was performed. For this purpose, a knowledge score was determined based on the percentage of correct responses: $0-40 \%$ correct responses were defined as "Poor" knowledge, 50-70\% correct responses as "Medium" knowledge, and 80-100\% correct responses as "Good" knowledge. The regression model was adjusted for the demographic variables (gender, age, and education). A $P$-value of less than 0.05 was considered statistically significant.

\subsection{Ethical considerations}

The study was conducted following the guidelines of the Declaration of Helsinki (WMA). Ethical approval was obtained from the Biosafety, Biosecurity \& Ethical Committee of Jahangirnagar University (Ref No: BBEC, JU/ M 2019 (11) 4). Participants were made aware of the purpose of the study and written informed consent was obtained from them.

\section{Results}

\subsection{Participants' characteristics}

Out of the 429 participants, $55.2 \%$ were males and $44.8 \%$ were females. In terms of age, $56.9 \%$ were $18-35$ years old, whereas $43.1 \%$ were older than 35 years. Also, $50.8 \%$ had some or complete undergraduate education. The demographic characteristics are presented in table 1. 


\subsection{Knowledge of antibiotics}

In general, participants demonstrated a lack of knowledge regarding the action and efficacy of antibiotics (Table 2). For example, only $16.8 \%$ knew that antibiotics are not effective in common colds. Also, a large percentage of the participants believed antibiotics are effective against viruses $(50.4 \%)$ or as painkillers $(47.9 \%)$. Moreover, only $56.1 \%$ were familiar with the concept of antibiotic resistance. However, most participants had correct knowledge about the inappropriate use of antibiotics such as non-prescription use (85\%), excessive use (80.2\%), and non-adherence $(76.9 \%)$.

\subsection{Antibiotic usage behavior}

The results of the multivariable logistic regression analysis of the association between the knowledge level of participants and their antibiotic usage behavior have been presented in table 3. About half (46.6\%) of the participants reported having taken antibiotics in the last six months. Although antibiotic use was less common in participants' with a greater level of knowledge, the association was not statistically significant $(p=0.081)$. Moreover, $20.5 \%$ of the respondents took antibiotics without a prescription and a lack of knowledge of antibiotics was associated with more self-medication $(p=0.037)$. Most participants $(76.9 \%)$ said they had completed the course of their last antibiotic therapy. No significant association was found between the level of knowledge and nonadherence $(p=0.113)$.

Table 1. Demographic characteristics of the participants $(\mathrm{N}=429)$.

\begin{tabular}{lll}
\hline Demographic Characteristic & Number & Percentage (\%) \\
\hline Gender & & \\
Male & 237 & 55.20 \\
Female & 192 & 44.80 \\
Age (years) & 244 & 56.90 \\
$18-35$ & 140 & 32.60 \\
$36-50$ & 45 & 10.50 \\
$>50$ & & \\
Education & 120 & 28.00 \\
Secondary (Grade 9-10) or below & 91 & 21.20 \\
Higher Secondary (Grade 11-12) & 218 & 50.80 \\
University (Ongoing/ completed) & & \\
\hline
\end{tabular}

Table 2. Responses to questions/ statements assessing knowledge.

\begin{tabular}{|c|c|c|c|c|}
\hline \multirow[t]{2}{*}{ Questions/ Statements $(\mathrm{N}=\mathbf{1 0})$} & \multirow{2}{*}{$\begin{array}{l}\text { Correct } \\
\text { Response }\end{array}$} & \multicolumn{3}{|c|}{ Participants' Response (\%) } \\
\hline & & Yes/Agree & No/ Disagree & Not sure \\
\hline \multicolumn{5}{|l|}{ Antibiotic action and efficacy } \\
\hline $\begin{array}{l}\text { 1. Do you think antibiotics work on most coughs and } \\
\text { colds? }\end{array}$ & No & 69.9 & 16.8 & 13.3 \\
\hline $\begin{array}{l}\text { 2. Do you think antibiotics are effective against } \\
\text { bacteria? }\end{array}$ & Yes & 66.6 & 8.7 & 24.7 \\
\hline $\begin{array}{l}\text { 3. Do you think antibiotics are effective against } \\
\text { viruses? }\end{array}$ & No & 50.4 & 22.5 & 27.2 \\
\hline 4. Do you think antibiotics work as painkillers? & No & 47.9 & 41.7 & 10.4 \\
\hline 5. Do you think antibiotics have any side effects? & Yes & 81.1 & 11.4 & 7.5 \\
\hline \multicolumn{5}{|l|}{ Antibiotic use and resistance } \\
\hline $\begin{array}{l}\text { 6. One should stop taking an antibiotic when } \\
\text { symptoms are improving. }\end{array}$ & Disagree & 29.6 & 65.5 & 4.9 \\
\hline $\begin{array}{l}\text { 7. It is okay to buy an antibiotic from pharmacies } \\
\text { without a doctor's prescription. }\end{array}$ & Disagree & 14.1 & 85.0 & 0.9 \\
\hline $\begin{array}{l}\text { 8. If taken too often, antibiotics are less likely to work } \\
\text { in the future. }\end{array}$ & Agree & 80.2 & 9.1 & 10.7 \\
\hline $\begin{array}{l}\text { 9. If the full course is not completed, antibiotics are } \\
\text { less likely to work in the future. }\end{array}$ & Agree & 76.9 & 10.0 & 13.1 \\
\hline $\begin{array}{l}\text { 10. Do you think pathogens can become resistant to } \\
\text { antibiotics? }\end{array}$ & Yes & 56.1 & 17.5 & 26.4 \\
\hline
\end{tabular}


Table 3. Association between participants' knowledge of antibiotics and their antibiotic usage behavior.

\begin{tabular}{|c|c|c|c|}
\hline Knowledge level & \% of participants & $\begin{array}{l}\text { Adjusted odds ratio (95\% } \\
\text { confidence interval) }\end{array}$ & $p$-value \\
\hline \multicolumn{4}{|c|}{ Outcome $=$ Participants took antibiotics in the last six months $(46.6 \%)$} \\
\hline Good & $34.1 \%$ & 1 & 0.081 \\
\hline Average & $49.0 \%$ & $1.81(1.06-3.07)$ & \\
\hline Poor & $51.6 \%$ & $1.80(0.95-3.43)$ & \\
\hline \multicolumn{4}{|c|}{ Outcome $=$ Participants self-medicated with antibiotics in the last six months $(20.5 \%)$} \\
\hline Good & $10.3 \%$ & 1 & 0.037 \\
\hline Average & $17.8 \%$ & $2.26(0.60-8.51)$ & \\
\hline Poor & $33.3 \%$ & $5.42(1.27-23.18)$ & \\
\hline \multicolumn{4}{|c|}{ Outcome $=$ Participants did not complete the full course of therapy $(23.1 \%)$} \\
\hline Good & $10.3 \%$ & 1 & 0.113 \\
\hline Average & $25.2 \%$ & $3.90(1.04-14.68)$ & \\
\hline Poor & $25.5 \%$ & $4.47(1.01-19.82)$ & \\
\hline
\end{tabular}

Poor, average, and good knowledge refer to $0-40 \%, 50-70 \%$, and $80-100 \%$ correct responses respectively.

\section{Discussion}

The results suggest that people have a poor understanding of the action and efficacy of antibiotics. The fact that only $16.8 \%$ knew antibiotics cannot cure most common colds and coughs is alarming. This also explains the findings in a study conducted in Bangladesh where cold, cough, and fever were the second leading cause of selfmedication with antibiotics (Biswas et al., 2014). Again, although antibiotics only work against bacterial infections, the majority of the participants believed antibiotics are also effective against viruses or as painkillers. This indicates that many people consider antibiotics a "cure-all" and are likely to take antibiotics for unrelated symptoms. Compared to other countries like Britain, Kuwait, and South Korea, the prevalence of such misconceptions among the people of Bangladesh was higher (Awad and Aboud, 2015; Kim et al., 2011; McNulty et al., 2007). However, most participants were aware of the fact that antibiotics can have side effects. Since side effects are associated with all drugs, a high rate of correct response in this particular question may be more related to people's knowledge of and experience with all drugs in general than their specific knowledge of antibiotics.

Compared with developed countries such as Britain and Hong Kong, the rates of antibiotic use, self-medication, and non-adherence were higher in this study (McNulty et al., 2007, You et al., 2008). The fact that almost half of the participants took antibiotics in the last six months implies that many of these people took antibiotics unnecessarily. The prevalence of self-medication found in this study (20.5\%) is very similar to that reported in another study conducted in Bangladesh (26.69\%) (Biswas et al., 2014). According to studies conducted in other Asian countries like Bhutan, India, and Indonesia, self-medication was practiced by $24-54 \%$ of the general public (Ahmad et al., 2012; Kurniawan et al., 2017; Tshokey et al., 2017). In this study, poor knowledge was associated with more self-medication. Results similar to ours were reported in studies performed in Lebanon and Indonesia (Jamhour et al., 2017; Kurniawan et al., 2017). However, in some other studies, self-medication was more prevalent among people with greater knowledge of antibiotics (Cheng et al., 2018; McNulty et al., 2007). Although the reasons behind this apparent discrepancy are unclear, the differences in health system and policy along with socioeconomic status of the people may be implicated.

\subsection{Implications of this study}

Given the high level of misconceptions and excessive use of antibiotics in Bangladesh, the first step should be the initiation of interventions to improve public knowledge of antibiotics and subsequently decrease overall antibiotic consumption. Now, whether better knowledge always translates into appropriate behavior is a matter of contention and knowledge was not significantly associated with two of the three parameters of antibiotic use tested in this study. There is, however, enough evidence that campaigns help to decrease antibiotic use in communities (Huttner et al., 2010; Sabuncu et al., 2009). Moreover, educating the public on the appropriate use of antibiotics has been mentioned as one of the primary intervention strategies by WHO for the containment of antibiotic resistance (WHO, 2001). If possible, social marketing strategies can be incorporated with antibiotic campaigns to elicit effective and sustainable change in antibiotic usage behavior (Edgar et al., 2008). Nevertheless, it is important to understand that apart from inappropriate knowledge and attitude of the public, irrational antibiotic use in the developing countries is often driven by uninformed healthcare providers as well as factors associated with health systems and policies including the availability of over-the-counter antibiotics, 
difficulty accessing health facilities and medical care, lack of trust in health professionals, untrained retail pharmacists, as well as inadequate regulatory policies (Servia-Dopazo and Figueiras, 2018; Torres et al., 2019). Therefore, initiatives should not be restricted to disseminating information; simultaneous improvement of the health systems and implementation of proper antibiotic policies is also needed.

\subsection{Limitations}

The study has a couple of limitations. First, the survey was conducted in the capital district Dhaka (primarily in suburban and urban areas) and the participants may not represent the whole population of Bangladesh. There is a high possibility that the level of misconceptions about and misuse of antibiotics in rural areas will be even higher. Second, there is a possibility of recall bias since participants had to remember their past use of antibiotics.

\section{Conclusions}

In summary, our study has identified two problems- a high level of misconceptions about antibiotics and inappropriate antibiotic use among the people of Bangladesh. Also, knowledge of antibiotics had a significant impact on participants' self-medication behavior. These findings present a strong case for taking measures to educate the public about antibiotics. In addition to this, educating the healthcare providers along with improvements of the healthcare systems and implementation of regulatory measures will be very crucial to achieve long-lasting results.

\section{Conflict of interest}

None to declare.

\section{References}

The Allopathic System (Prevention of Misuse) Ordinance, 1962; Available from: http://bdlaws.minlaw.gov.bd/act-details-324.html. 2020.

Ahmad A, S Parimalakrishnan, I Patel, N Kumar, T Balkrishnan and G Mohanta, 2012. Evaluation of selfmedication antibiotics use pattern among patients attending community pharmacies in rural India, Uttar Pradesh. J. Pharm. Res., 5: 765-768.

Ahmed I, MB Rabbi and S Sultana, 2019. Antibiotic resistance in Bangladesh: A systematic review. International Journal of Infectious Diseases, 80: 54-61.

Ahmed SM, N Naher, T Hossain and LB Rawal, 2017. Exploring the status of retail private drug shops in Bangladesh and action points for developing an accredited drug shop model: a facility based cross-sectional study. J. Pharm. Policy Pract., 10: 21.

Awad AI and EA Aboud, 2015. Knowledge, attitude and practice towards antibiotic use among the public in Kuwait. PloS One, 10: e0117910.

Biswas M, MN Roy, MIN Manik, MS Hossain, STA Tapu, M Moniruzzaman and S Sultana, 2014. Self medicated antibiotics in Bangladesh: a cross-sectional health survey conducted in the Rajshahi City. BMC Public Health, 14: 847.

Cheng J, C Coope, J Chai, I Oliver, A Kessel, D Wang and Y Sun, 2018. Knowledge and behaviors in relation to antibiotic use among rural residents in Anhui, China. Pharmacoepidemiol Drug Saf., 27: 652-659.

Chowdhury MMH, K Kubra, MT Islam, MM Rahman and ME Mehedy, 2015. Indiscriminate uses of antibiotics as a threat to public health demand implementation of effective drug practices and enhancement of public awareness in Bangladesh. European Journal of Scientific Research, 133: 187-195.

Edgar T, SD Boyd and MJ Palamé, 2008. Sustainability for behaviour change in the fight against antibiotic resistance: a social marketing framework. J. Antimicrob. Chemother., 63: 230-237.

Fahad B, A Matin, M Shill and K Asish, 2010. Antibiotic usage at a primary health care unit in Bangladesh. Australasian Medical Journal (Online), 3: 414.

Hoque R, SM Ahmed, N Naher, MA Islam, EK Rousham, BZ Islam and S Hassan, 2020. Tackling antimicrobial resistance in Bangladesh: A scoping review of policy and practice in human, animal and environment sectors. PLoS One, 15: e0227947.

Huttner B, H Goossens, T Verheij and S Harbarth. Characteristics and outcomes of public campaigns aimed at improving the use of antibiotics in outpatients in high-income countries. Lancet Infect. Dis., 10: 17-31.

Islam MS, 2006. A review on the policy and practices of therapeutic drug uses in Bangladesh. Calicut. Med. J., 4: e2. 
Jamhour A, A El-Kheir, P Salameh, PA Hanna and H Mansour, 2017. Antibiotic knowledge and self-medication practices in a developing country: a cross-sectional study. Am. J. Infect. Control, 45: 384-388.

Kim SS, S Moon and EJ Kim, 2011. Public knowledge and attitudes regarding antibiotic use in South Korea. J. Korean Acad. Nurs., 41: 742-749.

Kurniawan K, J Posangi and N Rampengan, 2017. Association between public knowledge regarding antibiotics and self-medication with antibiotics in Teling Atas Community Health Center, East Indonesia. Medical Journal of Indonesia, 26: 62-69.

McNulty CAM, P Boyle, T Nichols, P Clappison and P Davey, 2007. Don't wear me out-the public's knowledge of and attitudes to antibiotic use. J. Antimicrob. Chemother., 59: 727-738.

Read AF and RJ Woods, 2014. Antibiotic resistance management. Evol. Med. Public Health, 2014:147.

Sabuncu E, J David, C Bernède-Bauduin, S Pépin, M Leroy, P-Y Boëlle, L Watier and D Guillemot, 2009. Significant reduction of antibiotic use in the community after a nationwide campaign in France, 2002-2007. PLoS Med., 6: e1000084.

Saha S and MT Hossain, 2017. Evaluation of medicines dispensing pattern of private pharmacies in Rajshahi, Bangladesh. BMC Health Serv. Res., 17: 136.

Servia-Dopazo M and A Figueiras, 2018. Determinants of antibiotic dispensing without prescription: a systematic review. J. Antimicrob. Chemother., 73: 3244-3253.

Sutradhar KB, A Saha, NH Huda and R Uddin, 2014. Irrational use of antibiotics and antibiotic resistance in southern rural Bangladesh: perspectives from both the physicians and patients. Annu. Res. Rev. Biol., 4: 1421-1430.

Torres N, B Chibi, L Middleton, V Solomon and T Mashamba-Thompson, 2019. Evidence of factors influencing self-medication with antibiotics in low and middle-income countries: a systematic scoping review. Public Health, 168: 92-101.

Tshokey T, D Adhikari, T Tshering, S Wangmo and K Wangdi, 2017. Assessing the knowledge, attitudes, and practices on antibiotics among the general public attending the outpatient pharmacy units of hospitals in Bhutan: a cross-sectional survey. Asia Pac. J. Public Health, 29: 580-588.

WHO, 2001. WHO global strategy for containment of antimicrobial resistance. Geneva: World Health Organization; 2001.

You J, B Yau, K Choi, C Chau, Q Huang and S Lee, 2008. Public knowledge, attitudes and behavior on antibiotic use: a telephone survey in Hong Kong. Infection, 36: 153-157. 